\title{
New Approaches to Assess Fertility in Domestic Animals: Relationship between Arterial Blood Flow to the Testicles and Seminal Quality
}

\author{
Ana Velasco $^{1}$ (D) and Salvador Ruiz ${ }^{1,2, *(D)}$ \\ 1 Department of Physiology, Faculty of Veterinary Medicine, Campus Mare Nostrum, University of Murcia, \\ 30100 Murcia, Spain; ana.velascor@um.es \\ 2 Institute for Biomedical Research of Murcia, IMIB-Arrixaca, 30120 Murcia, Spain \\ * Correspondence: sruiz@um.es
}

Citation: Velasco, A.; Ruiz, S. New Approaches to Assess Fertility in Domestic Animals: Relationship between Arterial Blood Flow to the Testicles and Seminal Quality. Animals 2021, 11, 12. http://dx.doi.org/10.3390/ ani11010012

\section{Received: 24 October 2020}

Accepted: 16 December 2020

Published: 23 December 2020

Publisher's Note: MDPI stays neutral with regard to jurisdictional claims in published maps and institutional affiliations.

Copyright: () 2020 by the authors. Licensee MDPI, Basel, Switzerland. This article is an open access article distributed under the terms and conditions of the Creative Commons Attribution (CC BY) license (https: / / creativecommons.org/ licenses/by/4.0/).
Simple Summary: Reproduction is one of the most important economic factors at a production level. For that reason, the evaluation of the breeding soundness (BS) is of great relevance to secure high production rates. There is ongoing research to find new markers to bring closer breeding soundness examination (BSE) results to real fertility outcomes. Among the different methods to evaluate BS, ultrasonography is routinely used and it is the method of choice to evaluate the testicular parenchyma. Doppler mode allows the quantitative and qualitative evaluation of the irrigation of organs and can be used as an important diagnostic technique for evaluating the testicular irrigation. In humans and several animal species, a relationship between Doppler parameters of the testicular artery and seminal quality has been found. This suggests pulsed wave Doppler ultrasound measurements and indices could be proposed as objective parameters to evaluate testicular function.

\begin{abstract}
The early identification of infertile males improves reproduction efficiency at a production level and is essential to secure high production rates. Before entering a breeding program, males must pass an initial breeding soundness examination (BSE) which consist of several diagnostic exams whose end point is to estimate their future fertility. There is ongoing research to find new markers that allow better identification of fertile males. Doppler mode allows the quantitative and qualitative evaluation of the irrigation of organs. When evaluating the reproductive system, Doppler mode has been successfully used for the evaluation of the uterine and ovarian irrigation. In males, it is gaining relevance for the evaluation of testicular irrigation. Researchers have found a relationship between pulsed-wave Doppler velocimetric parameters and seminal quality in various domestic animal species. This suggests Doppler ultrasound parameters should be considered as objective parameters to evaluate testicular function. In this review, we analyze the results in the main domestic animal species and discuss the differences and similarities among the results. We also discuss the effect of the location of the measurements, breed, season and laterality in the measurement of Doppler velocimetric parameters as well as the impact and limitations of this method of assessing breeding soundness.
\end{abstract}

Keywords: breeding soundness evaluation; ultrasonography; doppler mode; testicular artery; fertility; resistive index; pulsatility index

\section{Introduction}

Reproductive technologies dictate the strategies that can be used to select genetically for traits that improve production. Of critical importance has been artificial insemination (AI). Given the central role of reproduction as a determinant of production efficiency and genetic selection in breeding programs, improvements in reproductive technologies will be crucial to face the challenges created by the increase in world population [1]. Reproduction is one of the most important economic factors in the livestock industry, based not only on 
the reproductive capacity of the female, but the male as well [2]. Farming systems' success depends on livestock management, especially improved reproductive performances. Both female and male genitals systems have to be sound to ensure successful breeding [3]. Male Breeding Soundness Evaluation (BSE) is an important component and common practice in domestic farming species. It is meant to predict the breeding capacity of males and enables us to identify and withdraw infertile males from the breeding program, selecting the best performing individuals as sires $[4,5]$.

Contemporary guidelines for BSE mainly center upon such aspects as breeding history, general health, physical examination, scrotal circumference and sperm morphology and motility [5-8]. Thus, the evaluation of semen quality is one of the major evaluations for the selection of males for breeding. Methods to assess the quality of semen before the male starts its reproductive life are required to predict their fertility potential [7]. Physical examination such as palpation of the testis has been proved inefficient when accurately assessing the testicular parenchyma and the presence of small lesions [5]. Increasingly, B-Mode ultrasonographic evaluation of reproductive organs is routinely used, as it is a safe, non-invasive technique for the identification of a normal testicular parenchyma, and it can be an important tool for the evaluation of testicular biometric parameters, which have been correlated with fertility potential $[3,7,8]$.

Due to the importance of BSE for the election of the best performing males and its direct effect in the flock fertility, it is necessary to develop other fertility markers for early BSE to improve productivity and genetic gain [4]. Testicular hemodynamic is the main route for the transport of oxygen, nutrients and other hormones to and from the testis [9]. Testicles receive its blood supply by the testicular artery. It originates from the abdominal aorta, and elongates more than necessary to compensate for the migration of the testis into the scrotum. As a consequence, it becomes extensively coiled before birth [10]. The testicular artery appears convoluted just before its entry to the testis. This convoluted part is termed supratesticular artery (STA) [9]. The vascular resistance in this vessel is therefore high, leaving capillary pressure in the testis lower than other organs [11]. The oxygen tension in the testis is low. The high metabolic activity in the seminiferous tubules is apparently adapted to this environment of low oxygen and low vascular perfusion pressure, and under normal conditions, the local vasculature is able to supply the testis with sufficient amounts of nutrients and oxygen [11].

Doppler ultrasonography has become the method of choice to evaluate blood supply of various organs. It is one of the simplest and most precise techniques for estimating blood flow, as it combines data concerning the anatomy and dynamic flow parameters [12]. Doppler effect was first described in 1842 by the Austrian physicist Christian Johann Doppler. When ultrasound contacts static surfaces, without movement, the frequency of the reflected echoes is the same as that of the emitted waves. On the contrary, when the waves collide with moving structures such as blood cells, the frequency of the reflected waves is different from that of the emitted waves, producing the well-known Doppler effect. The change in frequency of the reflected wave with respect to the emitted wave can be positive or negative [13-15]. There are two types of Doppler, continuous and pulsed [14]:

- Continuous Doppler: This type does not discriminate depth of field. All the blood vessels in the area are captured, regardless of the range of ultrasound applied.

- Pulsed Doppler: With this system you can choose the depth of the field to study, specifically evaluating the vessels in that area.

There are three different ways of representing the Doppler signal as an image: Color Doppler, Spectral Doppler and Power Doppler [14]:

- Color Doppler (CD): Provides a general idea of the presence and direction of blood flow. It encodes the frequency changes in red and blue. If the frequency is positive, the image will be red, while if it is negative, it will be blue. In addition to color, the brightness of the image is taken into account; the higher the brightness, the greater the frequency amplitude [14-16]. 
- $\quad$ Spectral Doppler (SD): Frequency changes are plotted on a graph as a function of time [13]. Analyses the speed of blood flow in a vessel, illustrating its hemodynamic [14-16].

- $\quad$ Power Doppler (PwD): It is the newest method. Unlike the others, it does not measure the speed or direction of the flow, but the intensity. It measures the number of cells that pass through a glass in a unit of time. The images are represented in color mode (orange-brown) in B mode. PwD is used in areas where blood flow is very slow, such as ovarian follicles or corpora lutea $[17,18]$.

The use of Doppler ultrasonography in animal reproduction research is more recent than in human research but not less significant. In animal reproduction, the significance and feasibility of the use of Doppler sonography was first used to study the vascularization of the female reproductive tract. Several studies have evidenced, through Doppler sonography, the relationship of blood flow and ovarian and uterine function throughout the estrous cycle and pregnancy [13].

The study of testicular hemodynamics is of great significance; in fact, one study that studied the blood flow in the testicular artery above the cord and on the surface of the testis in dogs showed that at both sides there is only about a $30 \%$ reduction in blood flow velocity between systole and diastole, compared with more than $90 \%$ in prostate artery [10]. This situation suggests that moderate disturbances in the blood supply to the organ could cause testicular malfunction [11].

Several researchers have studied the effect of reductions in testicular blood flow in spermatogenesis. Induced partial arteriosclerosis in the testicular artery of rams severely affected the seminiferous tubules, leading to an inflammatory reaction similar of that seen in infertile men [17]. In rats, it was observed that graded reductions of blood flow affects the early stages of spermatogenesis. When blood flow was reduced, there was a dose-related increase in the number of dying spermatogonia and early spermatocytes together with an increase in the number of PMN leukocytes accumulated in testicular blood vessels. Discrete reductions in flow may, therefore, have a large impact on sperm production [11].

In human medicine, the study of testicular vascularization by duplex Doppler ultrasonography is well established [18]. PwD ultrasonography is widely used to assess abnormalities of the male genital tract, and has proven to be a useful tool in the assessment of scrotal abnormalities, signs of testicular dysgenesis, inflammation of scrotal structures, testicular torsion and varicocele [19]. In veterinary medicine, the study of testicular vascularization was initially restricted to horses. Pozor and McDonnel (2004) concluded it is possible to characterize the testicular artery by ultrasonography and the importance of its measurement in two locations due to its convoluted course [20]. Following these results, more research was performed in other animal species, establishing physiological parameters of the testicular artery using $\mathrm{CD}$ and $\mathrm{SD}$ at different locations in stallions [20-22], jackass [23], dogs [21,24,25], felines [26], bull [27-29], rams [30-34], bucks $[9,12]$ and camelids [35].

The testicles require a stable blood supply for its function and maturation [36]. CD and SD of the blood flow towards the testicular parenchyma could reflect the functional changes occurring in the different reproductive periods [12].

The evaluation of the ovarian follicles and corpora lutea is most often not quantified by examining individual vessels, but by measuring the total area of colored pixels [15]. In the case of testicular vascularization, the internal spermatic artery and its branches are the major source of blood supply to the mammalian testis and epididymis [17]. In this case, the blood flow is evaluated in an individual vessel and it is typically evaluated semi-quantitatively using the Doppler indices [15]. These indices have been used to obtain information about blood flow and vascular impedance that cannot be obtained from velocity information alone. They depend on the measurements of the Peak Systolic Volume (PSV), End Diastolic Volume (EDV) and the mean velocity. The two widely used indexes are the Resistive Index (RI) and Pulsatility Index (PI) [36]. They are not a direct measure of blood flow, but rather describe the resistance to blood flow in vessels peripheral to the 
vessel being examined [15]. Figure 1 shows the typical waveform appearance of the spectral Doppler of one cardiac cycle in a buck and the parameters used for the semi-quantitative evaluation of the Doppler indices.

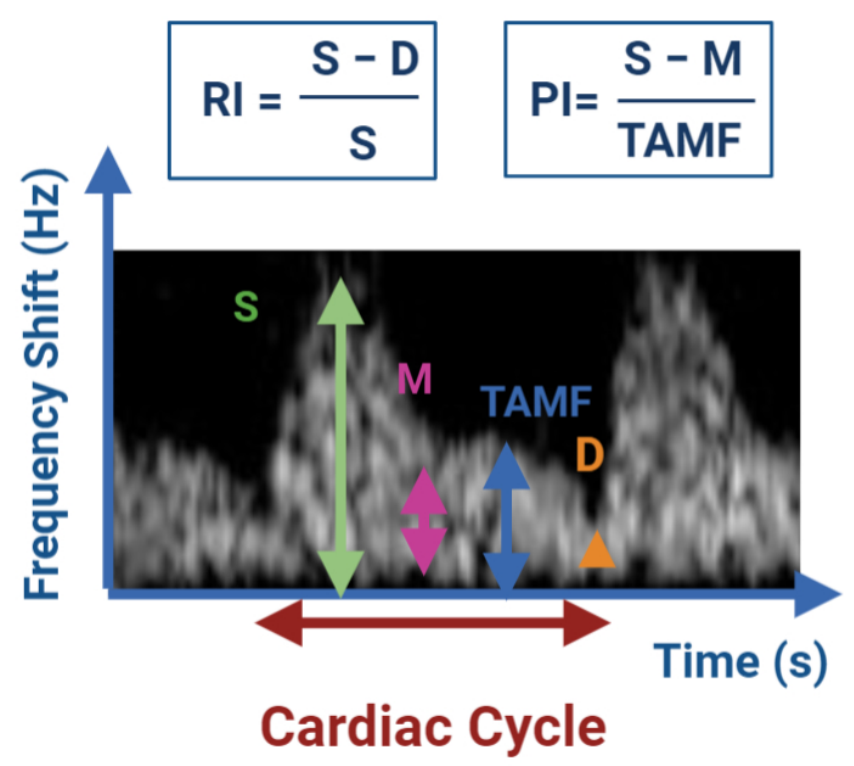

Figure 1. Semi-quantitative evaluation of blood flow by determination of the resistance to blood flow using the Doppler indices RI and PI. D: EDV; M: minimum frequency shift; S: PSV; TAMF: time averaged maximum frequency shift (TAMAX). Image adapted from Bollwein et al. [15].

Decreased values for RI and PI indicate decreases in the blood flow resistance and in turn increase in the testicular perfusion and continuous supply of oxygen and nutrients to the testis [14]. For the measurement of testicular blood flow, the RI has been used to date in both animals and humans [36].

When performing Doppler ultrasound examination, several aspects related to the immobilization of the animals, the placement of the probe and the correct identification of the testicular artery, must be taken into account to obtain valid results. A correct restraining of the animals is necessary to perform an adequate ultrasound exam since any movement may impair the correct caliper positioning during the exam [13-15]. In Figure 2, we can see an example of a correct restraining and probe positioning in a buck.

In the Doppler velocimetry assessment of the testicular artery, firstly, two-dimensional color Doppler scans have to be initially performed to visualize the testicular artery in the spermatic cord at the desired location. Secondly, blood vessels and flow must be identified using CD. Red indicating blood flow towards the transducer and blue indicating blood flow away from the transducer both in left and right testis [18]. Veins surround the STA forming the vascular cone. Therefore, before the assessment of Doppler parameters of the artery, a clear differentiation between the artery and veins should be done. To differentiate them, SD should be performed, the artery will typically have a spectral waveform representing the arterial pulse in each cardiac cycle. In the vein, however, the flow has no pulse and it is almost constant, as shown in Figure 3. After the identification of the vascular structures, the largest longitudinal section of the testicular artery at different locations must be identified. Then, the Doppler caliper has to be placed on the vessel lumen, and the arterial blood flow will be graphically represented as a wave. A minimum of three waves must be chosen and measured $[34,37,38]$ Furthermore, the Doppler shift is affected by the insonation angle between the Doppler beam and the flow direction $[16,18,19]$. The angle between the probe and the artery must be lower than $60^{\circ}$ so that the velocity values are reliable. Ideally the insonation angle should be between $45^{\circ}$ and $60^{\circ}$ [14]. 


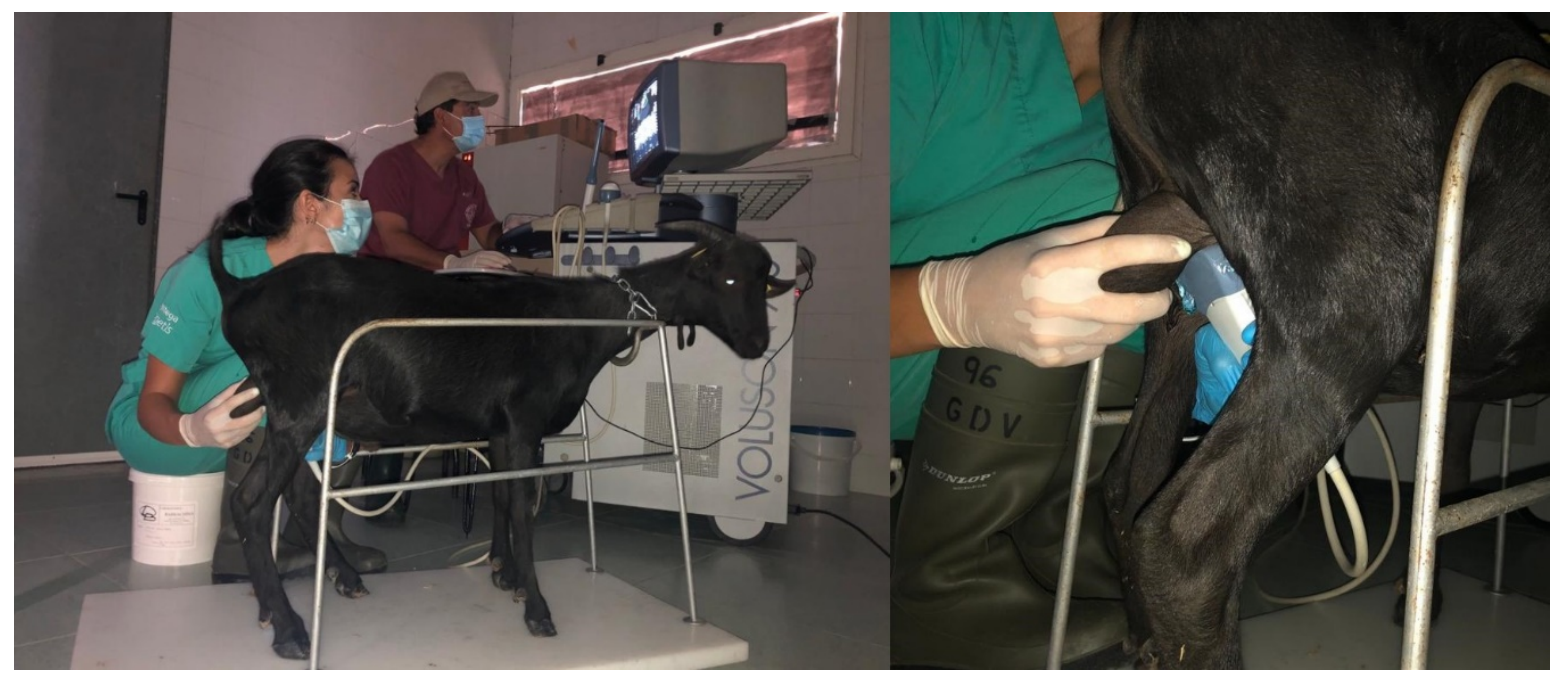

(a)

(b)

Figure 2. Correct Restraining (a) and ultrasound probe positioning (b) of a Murciano-Granadina buck for the Doppler ultrasound examination. Date: 3 July 2020.

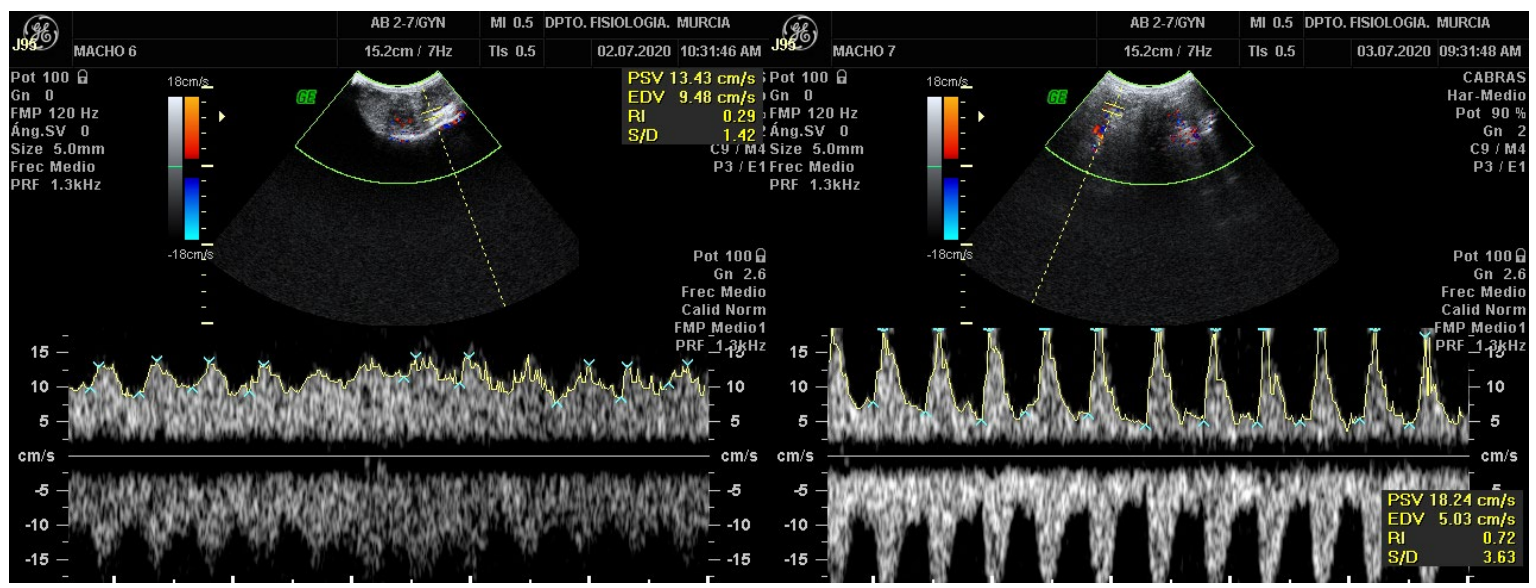

(a)

(b)

Figure 3. Pulsed-wave Doppler of the STA of a Murciano-Granadina breed buck. The pictures show the appearance of the pulsed-wave Doppler ultrasonography of the testicular vein (a) and of the testicular artery (b). Date: 3 July 2020.

\subsection{Relationship between Spermatogenesis and Doppler Ultrasonography Parameters}

The prediction of sires' reproductive performance is of major economic importance in the animal breeding industry. However, semen analysis does not always correlate with field fertility outcomes [39]. Despite controversy regarding the clinical value of semen analysis, male fertility investigation still relies on a standardized analysis of the semen parameters [40]. The evaluation of semen is an essential part of the andrological screening and helps to identify clear-cut cases of infertility. Usually, the sperm analysis includes recording of the volume, appearance, sperm concentration, sperm morphology and motility [41]. As standard semen analysis is a rather subjective technique, tools for computer-assisted semen analysis (CASA) have been developed. By use of CASA several specific motility parameters describing the movements of spermatozoa in a more detailed manner can be obtained [42]. The various individual movements that can be evaluated by CASA are shown in Figure 4, and include: curvilinear velocity (VCL), straight-line 
rectilinear velocity (VSL), average path velocity (VAP), velocity index (SVI), amplitude of lateral head displacement (ALH), linearity of curvilinear path (LIN), wobble (WOB), straightness (STR), beat-cross frequency (BCF) and mean angular displacement (MAD) [43].

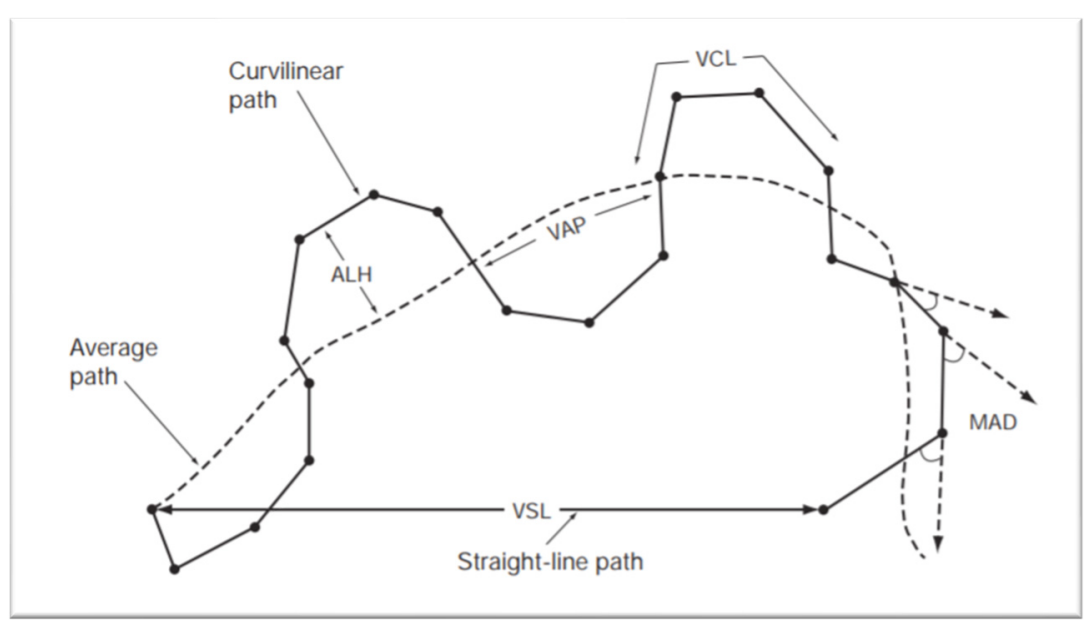

Figure 4. Standard terminology for variables measured by CASA system. Abbreviations include: Amplitude of lateral head displacement (ALH), average path velocity (VAP), curvilinear velocity (VCL), mean angular displacement (MAD), straight-line rectilinear velocity (VSL). World Health Organization Manual for the Evaluation of Human Semen [44].

The clinical andrological examination of a sire aims not only to determine the normality of testicular and epididymal function, as well of that of the genital tract of the male but also to estimate its potential capacity as a breeder [41]. Several researchers have studied the predictive value of arterial impedance of the testicular artery in relation to sperm analysis [45].

In human medicine, Biagiotti et al. (2002) investigated the differences in EDV, PSV, RI, follicular stimulating hormone and bilateral testicular volume in different groups of fertile and infertile men. Only RI and PSV were significantly associated with the sperm production rate score [45]. Pinggera et al. (2008) suggested that an RI $>0.6$ in humans might be related to a pathological sperm count in andrological patients [36]. In another study in varicocele patients, a negative association was found between progressive motility of spermatozoa and RI of the intraparenchymal arterial blood flow [46].

In veterinary medicine, the first attempts to study $\mathrm{SD}$ ultrasonography in the testicular artery were done in stallions. Pozor and McDonnell (2004) investigated the potential use of SD to characterize blood flow to the testis of stallions and to stablish reference values [20]. Bollwein et al. (2006) studied the relation between SD parameters and sperm quality. Blood flow was quantified using the PI and blood flow volume (BFV). No relationship was found between PI and sperm quantity or quality, although a connection was noticed between BFV and total sperm count per ejaculate [22]. Later on, Ortiz-Rodriguez et al. (2017) investigated the value of CD as a tool to evaluate testicular dysfunction in stallions. They found statistically significant differences in RI and PI values between fertile and sub fertile stallions, the latter group having higher RI and PI values. In contrast, fertile stallions displayed high EDV, TAMV, and BFV [21]. Similarly, in the jackass, RI and PI were strongly connected with CASA motility variable STR and sperm viability. Sperm concentration was inversely associated with PSV, EDV and TAMV. EDV was also inversely associated with CASA motility variables (VSL, LIN, STR and VAP) [23].

Several studies have characterized and established reference values of blood flow to the testicles in the dog $[18,24,25,47,48]$. Zelli et al. (2013) discovered a negative connection between PI and RI and the total progressive motility as well as a negative connection with the percentage of membrane intact sperms [47]. PSV was negatively associated with the number of live sperm [47]. This results contrast with those obtained by England et al. (2005) 
who failed to evidence a connection between RI and PI and the total sperm output or the percentage of live normal sperm [24]. In 2019, Trautwein et al. found a relationship between PSV with the velocity index, VCL and VAP [49]. In 2020, Lemos et al. found a relationship between PSV and EDV with sperm concentration as well as an inverse association between RI and PI at the STA with sperm membrane integrity. Additionally, a connection between EDV at the STA level with sperm concentration and an inverse association with sperm oxidative DNA damage were evidenced [25].

In the case of ruminants, the connection between $\mathrm{CD}$ ultrasonography parameters and future sperm quality was firstly assessed in the bull. A relationship was found between the RI of the marginal testicular artery (MTA) and total sperm in the ejaculate, immature sperm, teratoid sperms or "dag effect" spermatozoa [28]. In rams, no connection was found between motility and hemodynamic characteristics, but an association was found between the percentage of total sperm defects and RI and PI [33]. In bucks, Samir et al. (2020) demonstrated that the administration of melatonin decreased the RI and PI of testicular arteries, which was associated with significant increases in acrosome integrity, live/dead ratio, motility, and normal sperm morphology [9].

In camelids, differences in Doppler velocimetric parameters between fertile and infertile specimens were found. Fertile males yielded higher PSV and EDV values within the STAs. However, no significant differences between the RI of fertile and infertile males were found [35]. Previously reviewed results are presented in Table 1.

Table 1. Present research results proving the relation between arterial Doppler velocimetric indexes and seminal quality in domestic animal species.

\begin{tabular}{|c|c|}
\hline Species & Relation between CD Ultrasonography Parameters and Seminal Quality \\
\hline Bovine & $\begin{array}{l}\text { RI at the MA and IT associated with total sperm per ejaculate, inmmature sperm, teratoid sperm and dag effect sperm. } \\
\text { Gloria et al. [28] }\end{array}$ \\
\hline Ovine & RI and PI at the STA were associated with the total sperm deffects. Batissaco et al. [33] \\
\hline \multirow{2}{*}{ Equine } & Relationship between BFV at the STA and total sperm per ejaculate. Bollwein et al. [22] \\
\hline & Infertile stallions exhibited higher values of RI and PI at the MTA level. Ortiz-Rodriguez et al. [21] \\
\hline Donkey & $\begin{array}{l}\text { RI and PI at the capsular artery were associated CASA motility variables and sperm viability. Sperm concentration was } \\
\text { inversely associated with PSV, EDV and TAMV Gacem et al. [23] }\end{array}$ \\
\hline \multirow{4}{*}{ Canine } & $\begin{array}{l}\text { PSV had a inversed association with vitality. Negative connection between RI and PI with the percentage of intact } \\
\text { sperm membranes. Zelli et al. [47] }\end{array}$ \\
\hline & No association between RI and PI of the TA and total sperm output or vitality. England et al. [24] \\
\hline & Positive association between PSV at the proximal STA with SVI, VCL and VAP. Trautwein et al. [50] \\
\hline & $\begin{array}{l}\text { PSV was associated with sperm concentration. RI and PI of the STA were inversely associated with sperm membrane } \\
\text { integrity. EDV at the STA was associated with sperm concentration and inversely associated with sperm oxidative DNA } \\
\text { damage. Lemos et al. [25] }\end{array}$ \\
\hline Camelid & $\begin{array}{l}\text { Fertile males exhibited higher values of PSV and EDV at the STA level and higher values of PSV at the MTA level. } \\
\text { Kuzler et al. [35] }\end{array}$ \\
\hline
\end{tabular}

There is currently no proposed explanation for the positive relationship between RI and sperm count. Testicular arteries are target organs for androgens, and, in infertile men, testicular arteries have a narrow lumen due to enlarged endothelial cells, a thickened subendothelial layer and abundant adventitia rich in connective tissue fibers and ground substance [36]. The implication is that anatomical patterns of testicular arteries are related to spermatogenesis and that SD ultrasonography traces from the testicular artery can be considered as markers of spermatogenesis [36]. Studies where no association between SD ultrasonography parameters and seminal parameters was found justify this result, based on the hypothesis that the relationship of the testicular artery blood flow is more likely to be related to current rather than to future semen quality, due to the fact that endothelial thickening and changes in blood flow normally occur secondarily to testicular 
disease, while primary restriction of testicular artery diameter results in rapid testicular changes [24].

Another possible explanation for the differences found between studies performed in the same species can be due to the different vessels that were analyzed. Differences of Doppler velocimetric parameters have been assessed depending on the segment of the testicular artery which was evaluated [23,31,48]. Values also show discrepancies depending on the method used for semen recollection, for example in rams electroejaculation normally results in larger volumes and lower concentration [33].

\subsection{Influence of the Location of the Assessment on Doppler Indices and the Spectral Doppler Waveform}

In several animal species, up to five measurements at different locations of the testicular artery have been done $[48,50]$. The results of EDV, RI and PI testicular values are influenced by the location of the assessment. The locations that have been studied include proximal STA, distal STA, MTA and intratesticular [18]. In humans, the RI for capsular and intratesticular arteries were smaller than in the STA, while in stallions, values of mean $\mathrm{RI}$ in the marginal aspect of the artery were only slightly lower than in the convoluted aspect $[23,51]$. In dogs, Doppler velocimetry parameters show differences between the spermatic cord, MTA and intratesticular regions, with decreasing velocities as it approaches to testicular parenchyma $[48,50]$. PSV and EDV show a decreasing trend from STA region to the intra-testicular region, this changes resulted in a decreased RI and PI within the MTA and intratesticular artery [48].

Figure 5 shows a CD image of the STA and MTA. On pulsed-wave Doppler imaging, the testicular artery shows mostly a monophasic and non-resistive waveform pattern in dogs [47], rams [30] and goats [34]. However, SD imaging of the testicular artery in stallions showed a resistive biphasic waveform [20]. These differences are believed to derive from the position of the testes on its long axis, being oriented horizontally in horses, vertically in ruminants and cranio-ventrally in dogs [30].

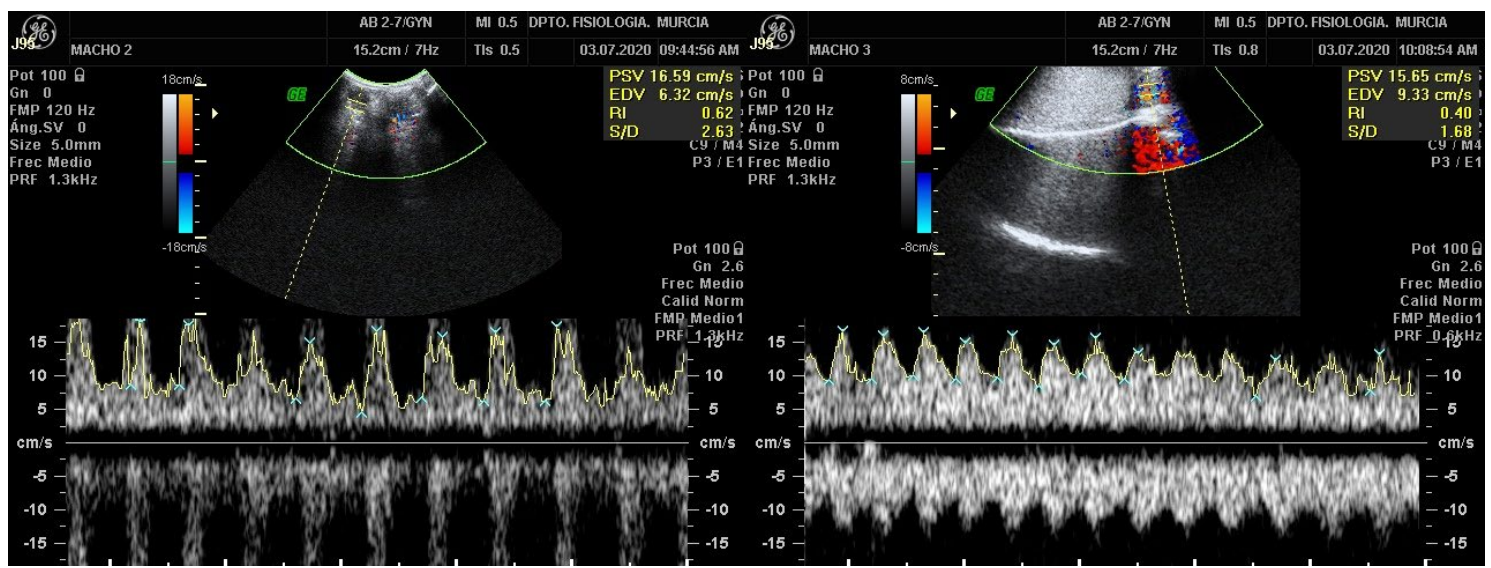

(a)

(b)

Figure 5. Ultrasonographic scan of the caprine testis using spectral pulsed-wave Doppler ultrasonography showing monophasic non-resistive wave form in the right STA (a) and in the MTA (b). Date: 3 July 2020.

Regional differences in wave morphology have been described. In dogs the waveform evolves from a semi-parabolic with high resistivity to intermediate in the cranial portions of the testicular artery to parabolic with low resistivity in the caudal and intratesticular portion. In stallions, an individual variation of waveform at different locations was evidenced. In general, the waveforms at the convoluted aspect of the TA were mostly resistive biphasic and evolved to non-resistive at monophasic at the MA level [20]. These findings can be explained by the fact that the testicular artery originates directly from the aorta, a vessel 
with high resistivity to blood flow. This resistivity decreases due to its prolongation and tortuosity with reduced thickness of the vascular endothelium as it approaches the testis. This directly influences the RI and PI [50].

\subsection{Influence of Breed and Size on Doppler Indices}

In many species of livestock, we can find breed differences with respect to the age of puberty, ejaculate volumes, sperm concentrations, and total sperm per ejaculate [52]. Little research has been done evaluating the effect of the breed on blood flow dynamic. It is hypothesized that animals with different genotypes could exhibit different physiological parameters of testicular hemodynamic. In fact, Junior et al. (2018) compared Doppler values of STA blood flow pattern in different breeds of bulls, the study found differences of the mean velocity, PI and RI between Aberdeen Angus, Bradford, Brangus, Hereford and Nelore bulls [27]. In another study performed in Nelore and Caracu bulls, significant differences between RI and PI where also found, meaning biometric ultrasonography characteristics of the testicular artery are affected by the genetic group [29]. The size of the animal also affects Doppler velocimetric parameters. Souza et al. (2014) evaluated Doppler velocimetry parameters in dogs of different sizes. Larger dogs showed higher velocities (EDV) at spermatic cord, while small dogs presented higher EDV at the level of the MTA. This difference might be explained by the length of the TA, which may vary according to weight [53]. When examining an animal, its breed and size should be taken into consideration when looking at the results.

\subsection{Influence of Season in Testicular Blood Flow Dynamics}

A large majority of farm animal express a more or less marked seasonal reproductive stationarity. The degree of reproductive seasonality expressed by an animal can vary markedly in intensity and timing. These variations depend on several factors including environmental factors, species, gender, genotype, reproductive status and amount of body energetic stores among other factors. As a consequence, most species show seasonal variations in their ovulation frequency, spermatogenic activity, gamete quality and also sexual behavior $[54,55]$. Some of the species which show a marked seasonality in breeding are small ruminants and equines [2,23].

In seasonal breeders, the volume of the ejaculate is high in the breeding season and decreases in the non-breeding season. Sperm concentration follows the opposite trend [54]. In 1999, Karagiannidis et al. described differences in seasonal semen quality in three dairy goat breeds born and raised in Mediterranean countries. There was a clear effect of photoperiod on their semen production [56]. These changes have also been noticed in ultrasonography. In goats, the testicular volume increased during the summer months reaching its highest values in September [12]. Similarly, in rams the mean testicular pixel intensity reached its lowest values during the winter and increased gradually reaching its highest values during summer [57].

Few studies have been conducted regarding annual variations in the SD ultrasonography parameters in mammals. Variations in SD ultrasonography parameters along the year were first described in stallions, in which Doppler parameters related with increased perfusion (PSV, EDV and TAMAX) presenting higher values during breeding season [58].

In caprine, to our knowledge, only two studies have been performed that describe annual variation in SD ultrasonography parameters. The first one was done in Sarda bucks by Strina et al. (2016). A decrease in the mean values of the RI of the testicular artery in the summer months was described, while the highest value of RI was detected in November [12]. The second experiment was performed in Shiba goats by Samir et al. (2018), described as non-seasonal breeders. Variations in the RI and PI were found, in opposition to the previous results the lowest values of PI and RI were found during winter and autumn [2].

Changes in the testicular blood flow among the seasons are attributable to two possible mechanisms, either due to variations in ambient temperature between the seasons 
or due to photoperiod, which is considered the principal factor influencing seasonality of reproduction in small ruminants [2]. In the summer season, increases in ambient temperature may result in concurrent increases in testicular temperature and, in turn, affect the testicular blood flow. In bulls submitted to short term testicular warming under anesthesia, the total blood flow was measured using a ultrasonic flow prove around the testicular artery and the testicular vein. Increases in testicular temperature and blood flow were related in Angus and Nelore bulls [59]. In rams, the blood flow to the testis was calculated using the technique of dilution of sodium p.aminohippurate. The blood blow increased spontaneously a $26 \%$ when their testis were exposed to direct heat [60]. In the study of Strina et al. (2016) a coincidental variation in testicular flow due to changes in ambient temperature may be the possible explanation to their results [12].

\subsection{Effect of Laterality in Testicular Blood Flow Dynamic}

Differences in testicular volumes on the left and right tests have been recorded in several animal species. In dogs, the PSV of the left spermatic cord was significantly higher than the right side [18]. Hedia et al. (2020) found that Doppler measures of RI as well as PI were slightly higher in the right testicular artery rather than the left testicular artery in rams [30]. In horses, no significant differences in RI, PI EDV and PSV were found between the left and right artery [20]. This difference might be explained because the left testicular artery arches over the renal vein, compressing the vessel and increasing velocity of blood flow in this area. The difference can also be explained due to the differences found between the volume of the left and right testis; a higher volume would require more blood supply [18].

\subsection{Limitations of the Use of Doppler in BSE}

The main limitation of this study is the workability. Differently from human medicine, the adoption of Doppler imaging technology in large animal practice is still limited. The two main factors that have contributed to this low use of Doppler technology at the farms is the availability and cost of portable devices and the relative lack of knowledge of practitioners [13]. Other possible limitations of this study include the fact that most of the objective measurements of blood flow performed by Doppler ultrasonography including the calculation of flow velocity and indices are usually performed in large straight arteries [13]. One example in human medicine is the common carotid artery [16]. The evaluation of the STA is especially challenging due to its coiled section before the entrance to the testis. As the STA is intertwined with the testicular vein it is sometimes difficult to assess differences between testicular artery and vein in the Doppler analysis [2]. Any movement of the animal may also impair the correct caliper positioning during the exam. Additionally, the Doppler shift is affected by the insonation angle between the Doppler beam and the flow direction [13-15]. Blood flow velocities measured as the PSV or EDV represent an angle dependent technique, so careful interpretation must be performed. Using the RI to assess blood blow represents the best option as it is independent of the angle [36].

\section{Conclusions}

Improving the reproductive performance of production animals continues to be one of the leading objectives in animal production research. SD has been used in humans and several animal species to objectively evaluate blood flow to the testes. In humans, studs, bulls, stallions, jackass, buck, rams and camelids, several SD velocimetric parameters including EDV, PSV, RI and PI have been associated with various parameters related to a better seminal quality. These results suggest SD ultrasound parameters could be proposed as objective parameters to evaluate testicular function and should be taken into consideration when performing the breeding soundness evaluation. Because of the variability found in these parameters depending on the location of the measurement, season, breed and laterality. Further research is needed to determine SD physiological 
parameters according to the species and breed, establishing reference values for the species within specific sizes.

Funding: This research was funded by The Spanish Ministry of Science and Innovation. Grant number: PID2019-106380RB-I00/AEI/10.13039/501100011033.

Informed Consent Statement: Not applicable.

Data Availability Statement: No new data were created or analyzed in this study. Data sharing is not applicable to this article.

Acknowledgments: We thank Ángel Poto (Murcian Institute of Agricultural and Food Research and Development- IMIDA) for his technical assistance during the research.

Conflicts of Interest: The authors declare no conflict of interest.

\section{References}

1. Hansen, P.J. Current and Future Assited Reproductive Technologies for Mammalian Farm Animals. In Current and Future Technologies and World Food Production. Advances in Experimental Medicine and Biology; Lamb, G.C., DiLorenzo, N., Eds.; Springer: New York, NY, USA, 2014; Volume 752, pp. 1-22. [CrossRef]

2. Samir, H.; Nyametease, P.; Nagaoka, K.; Watanabe, G. Effect of seasonality on testicular blood flow as determined by color Doppler ultrasonography and hormonal profiles in Shiba goats. Anim. Reprod. Sci. 2018, 197, 185-192. [CrossRef] [PubMed]

3. Boukhliq, R.; Allali, K.; El Tibary, A. Gross anatomy and ultrasonographic examination of the reproductive organs in rams and bucks. Acta Sci. Agron. 2018, 2, 226-240.

4. Singla, M.; Saini, A.L.; Kumar, A.; Kaswan, S.; Brar, P.S. Breeding soundness evaluation of stall-fed bucks using ultrasonography. Indian J. Anim. Sci. 2017, 87, 584-586.

5. Tibary, A.; Boukhliq, R.; El Allali, K. Ram and Buck Breeding Soundness Examination. Rev. Maroc. Sci Agron. Vét. 2018, 6, 241-255.

6. Griffin, P.G. The breeding soundness examination in the stallion. J. Equine Vet. Sci. 2000, 20, 168-171. [CrossRef]

7. Pinho, R.; Camilo, B.; Lima, D.; Villadiego, F.; Vergara, J.; Shiomi, H.; Cardoso, R.; Lopes, P.; Guimarães, S.; Guimarães, J. The use of ultrasonography in the reproductive evaluation of boars. Reprod. Domest. Anim. 2018, 53, 393-400. [CrossRef]

8. Eilts, B.E.; Pechman, R.D. B-mode ultrasound observations of bull testes during breeding soundness examinations. Theriogenology 1988, 30, 1169-1175. [CrossRef]

9. Samir, H.; Nyametease, P.; Elbadawy, M.; Nagaoka, K.; Sasaki, K.; Watanabe, G. Administration of melatonin improves testicular blood flow, circulating hormones, and semen quality in Shiba goats. Theriogenology 2020, 146, 111-119. [CrossRef]

10. Setchell, B.P.; Breed, W.G. Anatomy, vasculature, and innervation of the male reproductive tract. In Knobil Neill's Physiol Reprod, 3rd ed.; Neill, J., Ed.; Elsevier: Adelaide, Australia, 2006; Volume 1, pp. 771-825. [CrossRef]

11. Bergh, A.; Collin, O.; Lissbrant, E. Effects of Acute Graded Reductions in Testicular Blood Flow on Testicular Morphology in the Adult Rat. Biol. Reprod. 2001, 64, 13-20. [CrossRef]

12. Strina, A.; Corda, A.; Nieddu, S.; Solinas, M.G.; Lilliu, M.; Zedda, M.T.; Pau, S.; Ledda, S. Annual variations in resistive index (RI) of testicular artery, volume measurements and testosterone levels in bucks. Comp. Clin. Pathol. 2016, 25, 409-413. [CrossRef]

13. Viana, J.H.; Urashiro, E.K.; Siqueira, L.G.; Ghetti, A.; Areas, V.; Guimarães, C.R.; Palhão, M.P.; Camargo, L.S.A.; Fernandes, C.A. Doppler ultrasonography as a tool for ovarian management. Anim. Reprod. 2013, 10, 215-222.

14. Rubio, I.; Tirapu, M.; Zabalza, J. Ecografía Doppler: Principios básicos y guía práctica para residentes. In Proceedings of the Congreso de la Sociedad Española de Radiología Médica, Pamplona, España, 22-25 May 2014.

15. Bollwein, H.; Heppelmann, M.; Lüttgenau, J. Ultrasonographic Doppler Use for Female Reproduction Management. Vet. Clin. N. Am. 2016, 32, 149-164. [CrossRef] [PubMed]

16. Abdelrahman, M.A.; Oqlat, A.A.; Oqlat, M.A.; Matjafri, M.Z.; Oglat1, A.A.; Suardi, N. A review of Medical Doppler US. J. Med. Ultrasound 2018, 26, 115-117. [CrossRef]

17. Markey, C.M.; Jequier, A.M.; Meyer, G.T.; Martin, G.B. Relationship between testicular morphology and sperm production following ischaemia in the ram. Reprod. Fertil. Dev. 1995, 7, 119-128. [CrossRef] [PubMed]

18. De Souza, M.B.; Barbosa, C.D.C.; Pereira, B.S.; Monteiro, C.L.B.; Pinto, J.N.; Linhares, J.C.S.; Da Silva, L.D.M. Doppler velocimetric parameters of the testicular artery in healthy dogs. Res. Vet. Sci 2014, 96, 533-536. [CrossRef] [PubMed]

19. Lotti, F.; Maggi, M. Color-Doppler Ultrasound and New Imaging Techniques in Andrological Examination. In Endocrinology of Testis and Male Reproduction, 1st ed.; Simoni, M., Huhtaniemi, I.T., Eds.; Springer: New York, NY, USA, 2017; Volume 1, pp. 555-621. [CrossRef]

20. Pozor, M.A.; McDonnell, S.M. Color Doppler ultrasound evaluation of testicular blood flow in stallions. Theriogenology 2004, 61, 799-810. [CrossRef]

21. Ortiz-Rodriguez, J.M.; Anel-López, L.; Martín-Muñoz, P.; Álvarez, M.; Gaitskell-Phillips, G.; Anel, L.; Rodríguez-Medina, P.; Peña, F.J.; Ferrusola, C.O. Doppler ultrasound as a tool for the diagnosis of chronic testicular dysfunction in stallions. PLoS ONE 2017, 12, e0175878. [CrossRef] 
22. Bollwein, H.; Scheibenzuber, E.; Stolla, R.; Echte, A.F.; Sieme, H. Testicular blood flow in the stallion: Variability and its relationship to sperm quality and fertility. Pferdeheilkd Equine Med. 2006, 22, 123-133. [CrossRef]

23. Gacem, S.; Papas, M.; Catalan, J.; Miró, J. Examination of jackass (Equus asinus) accessory sex glands by B-mode ultrasound and of testicular artery blood flow by colour pulsed-wave Doppler ultrasound: Correlations with semen production. Reprod. Domest. Anim. 2020, 55, 181-188. [CrossRef]

24. England, G.; Bright, L.; Pritchard, B.; Bowen, I.M.; De Souza, M.B.; Silva, L.; Moxon, R. Canine reproductive ultrasound examination for predicting future sperm quality. Reprod. Domest. Anim. 2017, 52, 202-207. [CrossRef]

25. Lemos, H.; Dorado, J.; Hidalgo, M.; Gaivão, I.; Martins-Bessa, A. Assessment of Dog Testis Perfusion by Colour and PulsedDoppler Ultrasonography and Correlation With Sperm Oxidative DNA Damage. Top. Companion Anim. Med. 2020, 41, 1-19. [CrossRef] [PubMed]

26. De Brito, M.; Feliciano, M.A.R.; Coutinho, L.; Uscategui, R.A.R.; Simões, A.; Maronezi, M.; De Almeida, V.; Crivelaro, R.; Gasser, B.; Pavan, L.; et al. Doppler and Contrast-Enhanced Ultrasonography of Testicles in Adult Domestic Felines. Reprod. Domest. Anim. 2015, 50, 730-734. [CrossRef] [PubMed]

27. Junior, F.A.B.; Junior, C.K.; Favaro, P.D.C.; Pereira, G.R.; Morotti, F.; Menegassi, S.R.O.; Barcellos, J.O.J.; Seneda, M.M. Effect of breed on testicular blood flow dynamics in bulls. Theriogenology 2018, 118, 16-21. [CrossRef] [PubMed]

28. Gloria, A.; Carluccio, A.; Wegher, L.; Robbe, D.; Valorz, C.; Contri, A. Pulse wave Doppler ultrasound of testicular arteries and their relationship with semen characteristics in healthy bulls. J. Anim. Sci. Biotechnol. 2018, 9, 1-7. [CrossRef] [PubMed]

29. Rodrigues, N.N.; Rossi, G.F.; Vrisman, D.P.; Taira, A.R.; Souza, L.L.; Zorzetto, M.F.; Bastos, N.M.; De Paz, C.C.P.; De Lima, V.F.M.H.; Monteiro, F.M.; et al. Ultrasonographic characteristics of the testes, epididymis and accessory sex glands and arterial spectral indices in peri- and post-pubertal Nelore and Caracu bulls. Anim. Reprod. Sci. 2019, 212, 106235. [CrossRef] [PubMed]

30. Hedia, M.G.; El-Belely, M.S.; Ismail, S.T.; El-Maaty, A.M.A. Evaluation of testicular blood flow and ultraso-nographic measurements in rams with emphasis on laterality. J. Adv. Vet. Res. 2020, 10, 17-20.

31. Camela, E.S.C.; Nociti, R.P.; Santos, V.J.C.; Macente, B.I.; Murawski, M.; Vicente, W.R.R.; Bartlewski, P.M.; Oliveira, M.E.F. Changes in testicular size, echotexture, and arterial blood flow associated with the attainment of puberty in Dorper rams raised in a subtropical climate. Reprod. Domest. Anim. 2018, 54, 131-137. [CrossRef]

32. Elbaz, H.; Elweza, A.; Sharshar, A. Testicular Color Doppler Ultrasonography in Barki Rams. Alex. J. Veter Sci. 2019, 61, 39. [CrossRef]

33. Batissaco, L.; Celeghini, E.C.C.; Pinaffi, F.L.V.; De Oliveira, B.M.M.; De Andrade, A.F.C.; Recalde, E.C.S.; Fernandes, C.B. Correlações entre a hemodinâmica testicular e as características espermáticas em carneiros. Braz. J. Veter-Res. Anim. Sci. 2014, 50, 384. [CrossRef]

34. Samir, H.; Sasaki, K.; Ahmed, E.; Karen, A.; Nagaoka, K.; El Sayed, M.; Taya, K.; Watanabe, G. Effect of a single injection of gonadotropin-releasing hormone $(\mathrm{GnRH})$ and human chorionic gonadotropin (hCG) on testicular blood flow measured by color Doppler ultrasonography in male Shiba goats. J. Vet. Med. Sci. 2015, 77, 549-556. [CrossRef]

35. Kutzler, M.; Tyson, R.; Grimes, M.; Timm, K. Determination of testicular blood flow in camelids using vascular casting and color pulsed-wave Doppler ultrasonography. Vet. Med. Int. 2011, 2011, 638602. [CrossRef] [PubMed]

36. Pinggera, G.-M.; Mitterberger, M.; Bartsch, G.; Strasser, H.; Gradl, J.; Aigner, F.; Pallwein, L.; Frauscher, F. Assessment of the intratesticular resistive index by colour Doppler ultrasonography measurements as a predictor of spermatogenesis. BJU Int. 2008, 101, 722-726. [CrossRef] [PubMed]

37. Zaidi, J.; Jurkovic, D.; Campbell, S.; Pittrof, R.; Mcgregor, A.; Tan, S.L. Physiology: Description of circadian rhythm in uterine artery blood flow during the peri-ovulatory period. Hum. Reprod. 1995, 10, 1642-1646. [CrossRef] [PubMed]

38. Mbaeri, T.U.; Orakwe, J.C.; Nwofor, A.M.E.; Oranusi, C.K.; Mbonu, O.O. Ultrasound measurements of testicular volume: Comparing the three common formulas with the true testicular volume determined by water displacement. Afr. J. Urol. 2013, 19, 69-73. [CrossRef]

39. Kumaresan, A.; Das Gupta, M.; Datta, T.K.; Morrell, J.M. Sperm DNA Integrity and Male Fertility in Farm Animals: A Review. Front. Vet. Sci. 2020, 7, 321. [CrossRef]

40. Franken, D.R.; Oehninger, S. Semen analysis and sperm function testing. Asian J. Androl. 2012, 14, 6-13. [CrossRef]

41. Rodríguez-Martínez, H. State of the art in farm animal sperm evaluation. Reprod. Fertil. Dev. 2007, 19, 91-101. [CrossRef]

42. Larsen, L.; Scheike, T.; Jensen, T.K.; Bonde, J.P.; Ernst, E.; Hjollund, N.H.; Zhou, Y.; Skakkebæk, N.E.; Giwercman, A. Computerassisted semen analysis parameters as predictors for fertility of men from the general population. Hum. Reprod. 2000, 15, 1562-1567. [CrossRef]

43. Michos, I.A.; Basioura, A.G.; Boscos, C.M.; Tsakmakidis, I.A. Proper use and impact of "Computer Assited Semen Analysis" technique on semen evaluation of farm animals. J. Hellenic Vet. Med. Soc. 2013, 64, 267-274. [CrossRef]

44. Cooper, T.G. WHO Laboratory Manual for the Examination and Processing of Human Semen, 5th ed.; EHO Press: Geneva, Switzerland, 2010; p. 139.

45. Biagiotti, G.; Cavallini, G.; Modenini, F.; Vitali, G.; Gianaroli, L. Spermatogenesis and spectral echo-colour Doppler traces from the main testicular artery. BJU Int. 2002, 90, 903-908. [CrossRef]

46. Rehman, K.U.; Zaneb, H.; Qureshi, A.B.; Yousaf, M.S.; Numan, A.; Majeed, K.A.; Rabbani, I.; Khan, T.M.; Rehman, H. Correlation between Testicular Hemodynamic and Semen Quality Indices in Clinical Varicocele Patients in Pakistan. Biomed. Res. Int. 2019, 2019, 1-6. [CrossRef] 
47. Zelli, R.; Troisi, A.; Elad Ngonput, A.; Cardinali, L.; Polisca, A. Evaluation of testicular artery blood flow by Doppler ultrasonography as a predictor of spermatogenesis in the dog. Res. Vet. Sci. 2013, 95, 632-637. [CrossRef] [PubMed]

48. De Souza, M.B.; Barbosa, C.C.; England, G.; Filho, A.C.M.; Sousa, C.V.S.; De Carvalho, G.G.; Silva, H.V.R.; Pinto, J.N.; Linhares, J.C.; Da Silva, L.D.M. Regional differences of testicular artery blood flow in post pubertal and pre-pubertal dogs. BMC Vet. Res. 2015, 11, 47-53. [CrossRef] [PubMed]

49. Trautwein, L.; Cardoso, G.S.; Almeida, A.; Hidalgo, M.; Neta, J.; Paranzini, C.; Souza, A.K.; Martins, M.I.M. Correlation between sperm kinetics and Doppler velocimetry of testicular artery with kinetics and sperm morphology in dogs. Reprod. Domest. Anim. 2019, 16, 84 .

50. Trautwein, L.G.C.; Souza, A.K.; Martins, M.I.M. Can testicular artery Doppler velocimetry values change according to the measured region in dogs? Reprod. Domest. Anim. 2019, 54, 687-695. [CrossRef] [PubMed]

51. Middleton, W.D.; Thorne, D.A.; Melson, G.L. Color Doppler ultrasound of the normal testis. Am. J. Roentgenol. 1989, $152,293-297$. [CrossRef]

52. Nuti, L.C. Goat Semen Collection and Processsing. Cornell Univ. 2016, 40, 184-185. [CrossRef]

53. De Souza, M.B.; Filho, A.C.M.; Sousa, C.V.; Monteiro, C.L.; Carvalho, G.G.; Pinto, J.N.; Linhares, J.C.; Da Silva, L.D.M. Triplex Doppler evaluation of the testes in dogs of different sizes. Pesqui. Vet. Bras. 2014, 34, 1135-1140. [CrossRef]

54. Chemineau, P.; Malpaux, B.; Brillard, J.P.; Fostier, A. Seasonality of reproduction and production in farm fishes, birds and mammals. Animal 2007, 1, 419-432. [CrossRef]

55. Ungerfeld, R.; Bielli, A. Seasonal and social factors affecting reproduction. In Animal Reproduction in Livestock; Encycl Life Support System: Paris, France, 2012; pp. 1-5.

56. Karagiannidis, A.; Varsakeli, S.; Karatzas, G. Characteristics and seasonal variations in the semen of alpine saanen and samascus goat bucks born and raised in Greece. Theriogenology 2000, 53, 1285-1293. [CrossRef]

57. Hedia, M.; El-Belely, M.; Ismail, S.; El-Maaty, A. Seasonal changes in testicular ultrasonogram pixel-intensity and their association with semen characteristics in rams. Asian Pac. J. Reprod. 2020, 9, 49-54. [CrossRef]

58. Farm, C.; Verstegen, J. Effect of seasonality on testicular blood flow in mature stallions. Anim. Reprod. Sci. 2006, 94, 144-145. [CrossRef]

59. Rizzoto, G.; Ferreira, J.; Garcia, H.M.; Teixeira-Neto, F.; Bardella, L.; Martins, C.; Silva, J.; Thundathil, J.; Kastelic, J. Short-term testicular warming under anesthesia causes similar increases in testicular blood flow in Bos taurus versus Bos indicus bulls, but no apparent hypoxia. Theriogenology 2020, 145, 94-99. [CrossRef] [PubMed]

60. Mieusset, R.; Sowerbutts, S.F.; Zupp, J.L.; Setchell, B.P. Increased flow of testicular blood plasma during local heating of the testes of rams. J. Reprod. Fertil. 1990, 94, 345-352. [CrossRef] 